\title{
The Dynamic Behaviour of the Floor of a Surrogate Vehicle Under Explosive Blast Loading
}

\author{
Nicolas Newell ${ }^{1}$, William Neal ${ }^{2}$, Thanyani Pandelani ${ }^{3}$, David Reinecke ${ }^{3}$, \\ William G Proud ${ }^{2} \&$ Spyros D Masouros ${ }^{1}$ \\ ${ }^{1}$ Department of Bioengineering, Imperial College London, London SW7 2AZ, United Kingdom \\ ${ }^{2}$ Institute of Shock Physics, Imperial College London, SW7 2AZ, United Kingdom \\ ${ }^{3}$ Department of Defence, Peace, Safety and Security, Council for Scientific and Industrial Research (CSIR), PO \\ Box 395, Pretoria, 0001, South Africa \\ Correspondence: Nicolas Newell, Department of Bioengineering, Imperial College London, London SW7 2AZ, \\ United Kingdom. E-mail: n.newell09@imperial.ac.uk
}

Received: December 27, 2015 Accepted: January 8, 2016 Online Published: January 29, 2016

doi:10.5539/jmsr.v5n2p65 URL: http://dx.doi.org/10.5539/jmsr.v5n2p65

\begin{abstract}
Improvised Explosive Devices have been the signature weapon in the recent conflicts in Iraq and Afghanistan. High-rate axial forces exerted by the vehicle floor to the lower limbs of occupants have been the cause of severe injuries. In order to gain a greater understanding of the mechanisms of these injuries so that countermeasures can be developed, one is required to know how the vehicle floor behaves; therefore, the purpose of this study was to characterise the behaviour of a vehicle floor surrogate to a range of explosive loads. Explosive loads between 1 and $6 \mathrm{~kg}$ TNT were detonated beneath a vehicle floor surrogate resulting in peak floor velocities between 5.8 and $80.5 \mathrm{~m} / \mathrm{s}$ reached in a time between 0.10 and $3.13 \mathrm{~ms}$. The data can now be used to (a) test numerical models of blast and its interaction with structures for validity, and (b) ensure that the velocity profiles replicated in a laboratory environment to understand human tolerance to injury are relevant to the blast process. These will ensure that preventive measures are developed based on realistic physical and numerical models of injury.
\end{abstract}

Keywords: blast, photonic doppler velocimetry, injury, vehicle, IED

\section{Introduction}

The use of the improvised explosive device (IED) from insurgents against Coalition Troops and civilians has epitomised the recent conflicts in Iraq and Afghanistan. A significant number of injuries have been sustained by vehicle occupants during under-vehicle explosions in which the deformation of the floor of the vehicle subjected the lower limb to high-rate axial loading (Ramasamy et al., 2011c).

The physics of blast have been described in more detail elsewhere (Freidlander, 1946; Ramasamy et al., 2011b). Briefly, following detonation a shock wave propagates through the explosive instigating an almost instantaneous chemical reaction which produces hot, high-pressure gas that forms behind the detonation wave. This gas expands rapidly, and, if the explosive is buried, pushes material outwards from the surface, throwing soil ejecta up into the vehicle. There is an instantaneous sharp rise in pressure within the air surrounding the explosion, rapidly attaining its peak overpressure. Due to the inertial effect in air, overexpansion results in below ambient atmospheric pressures. On interaction with the vehicle the blast wave causes rapid deformation of the floor, causing axial loading to the lower limbs of occupants inside.

There are many factors that influence the behaviour of the floor during an under-vehicle explosion including vehicle design, size of explosive, depth of burial, and properties of the soil to name but a few (Ramasamy et al., 2011c). Due to the highly dynamic and somewhat unpredictable loading environment it is unlikely that there are distinct levels of severities of velocities, accelerations or displacements that define the response of the floor to certain threats; however, it is important to have an understanding of the possible range of floor behaviours.

In order to understand lower limb injuries seen in under-vehicle explosions and quantify human tolerance to such an insult, traumatic injury simulators have been developed by a number of research groups (Bailey et al., 2013, 2014; Masouros et al., 2013; McKay \& Bir, 2008; Pandelani et al., 2010; Quenneville, 2010; Yoganandan et al., 2015). These simulators aim to replicate the loading applied to the lower limbs of vehicle occupants by accelerating 
a mass to a target velocity or acceleration. Often, justifications for these target velocities or accelerations are anecdotal.

Scaled blast simulations have been carried out at the Test Rig for Occupant Safety Systems (TROSS ${ }^{\mathrm{TM}}$, developed by Industrieanlagen-Betriebsgesellschaft (IABG) in conjunction with WTD 91, Germany). TROSS ${ }^{\mathrm{TM}}$ is a surrogate vehicle floor test rig designed such that scaled blasts of 0.1 to $1 \mathrm{~kg}$ TNT (corresponding to full scale loads of 2-10 kg of TNT) can be detonated beneath an elastic, deformable membrane, bottom plate to replicate loads from a landmine detonation under a light armoured or logistic military vehicle. The rig is designed such that an anthropometric test device (ATD) can be seated with the feet resting on the bottom plate (North Atlantic Treaty Organisation HFM-090 TG 25, 2007). The TROSS ${ }^{\mathrm{TM}}$ is capable of reproducing velocities up to $60 \mathrm{~m} / \mathrm{s}$, with peak velocities being reached within $2 \mathrm{~ms}$. The results from tests performed using TROSS ${ }^{\mathrm{TM}}$ have been used to define input loading conditions for controlled laboratory experiments with cadavers or surrogates (Bir et al., 2008; Horst and Simms, 2005; Manseau and Keown, 2005; Pandelani et al., 2010); the effect, however of the use of a small elastic deformable membrane plate rather than a fully intact steel plate similar to those found in military vehicles on the accuracy of the simulation is unknown.

Held (2009) investigated experimentally, both the global impulses of mines, as well as the bulging of vehicle floors caused by focused blasts. In the global impulse investigation, $5 \mathrm{~kg}$ cylindrical explosive charges (diameter to height ratio of 3:1) were detonated beneath momentum blocks positioned $500 \mathrm{~mm}$ above the ground. Three different charge positions were investigated; lying on the ground, level with the ground (flush buried) and buried $100 \mathrm{~mm}$ deep. The velocity of the momentum blocks during the explosive event was measured through analysis of two flash X-ray exposures ( 2 and $10 \mathrm{~ms}$ after detonation). Impulse density was calculated by dividing the momentum (velocity $\times$ mass) by the cross-sectional area of the momentum block. The greatest impulse density at the charge axis was seen when charges were lying on the ground, with the impulse density at the charge axis dropping by approximately $15 \%$ when charges were buried flush with the surface and by $25 \%$ when buried $100 \mathrm{~mm}$ deep. At radial distances greater than approximately $125 \mathrm{~mm}$ from the charge axis, a higher impulse density was seen when the charge was buried in comparison to lying on the ground, demonstrating the damping effect of sand on focused blast waves. To investigate the bulging of the vehicle floor an $8 \mathrm{~kg}$ cylindrical TNT-charge (diameter to height ratio of $3: 1$ ) was positioned in a steel pit, $500 \mathrm{~mm}$ below a $25 \mathrm{~mm}$ thick high-grade steel plate. The displacementtime characteristics were measured using a custom made device (Held, 2009). Approximately $0.16 \mathrm{~ms}$ after detonation the plate had deformed by $16 \mathrm{~mm}$, reaching its maximum velocity of approximately $140 \mathrm{~m} / \mathrm{s}$. Interestingly, a linear increase in velocity was seen between 0.02 and $0.14 \mathrm{~ms}$, suggesting a constant acceleration of approximately $100,000 \mathrm{~g}$. While this study gives an insight into the behaviour of a plate when subjected to explosive loading, velocity was only measured at the centre of the plate using a low resolution measuring device. Additionally, the effect of charge size was not investigated and the consequence of using just a $25 \mathrm{~mm}$ thick steel plate rather than attempting to replicate a whole vehicle in terms of structure and mass on the overall behaviour is unknown.

Unfortunately, there is very little information in the public domain with regards to blast tests on military vehicles and therefore much of the work carried out in this area cannot be reviewed critically here. Results from a limited number of tests of this kind have been referred to by others (Table 1) and give an envelope of potential floor behaviours in an under-vehicle explosion.

Table 1. References made to unpublished live blast data in the literature.

\begin{tabular}{|c|c|c|c|c|}
\hline Author & Reference to live blast data from paper & $\begin{array}{l}\text { Max. vel. } \\
(\mathrm{m} / \mathrm{s})\end{array}$ & $\begin{array}{l}\text { Max. acc. } \\
\text { (g) }\end{array}$ & $\begin{array}{l}\text { Max. disp. } \\
\quad(\mathrm{mm})\end{array}$ \\
\hline Wang et al. (2001) & $\begin{array}{l}\text { "In a medium-sized armoured vehicle, localised floor } \\
\text { average acceleration and peak velocity may typically } \\
\text { exceed } 100 \mathrm{~g} \text { and } 12 \mathrm{~m} / \mathrm{s} \text {." }\end{array}$ & $>12$ & $>100$ & - \\
\hline $\begin{array}{l}\text { Manseau and } \\
\text { Keown (2005) }\end{array}$ & $\begin{array}{l}\text { "... [the injury simulator results in] a Hybrid-III tibia } \\
\text { response comparable to that of full-scale mine testing" }\end{array}$ & 5 & - & - \\
\hline $\begin{array}{c}\text { Manseau and } \\
\text { Lapointe (2005) }\end{array}$ & $\begin{array}{c}\text { "The loading produced by small charges detonated under } \\
\text { the TROSSTM is comparable to a real mine detonation } \\
\text { under a military vehicle." }\end{array}$ & $3.4-8.5$ & - & - \\
\hline $\begin{array}{l}\text { McKay (2010) and } \\
\text { McKay and Bir } \\
\text { (2008) }\end{array}$ & $\begin{array}{l}\text { "full scale military vehicle blast test data were reviewed } \\
\text { for a range of blast magnitudes... Review of this data } \\
\text { revealed three distinct levels of impact severity" }\end{array}$ & 7 & & \\
\hline
\end{tabular}


An alternative to experimental characterisation is to simulate an under-vehicle explosion numerically. Williams and Fillion-Gourdeau (2002) developed a finite element model of a light armoured vehicle and simulated the detonation of a $6 \mathrm{~kg}$ mine buried $88.1 \mathrm{~mm}$ into the soil beneath the left inside edge of the middle wheel. This model predicted that the floor would reach approximately $27 \mathrm{~m} / \mathrm{s}$ within $10 \mathrm{~ms}$, unfortunately it was not compared against experimental data.

While a general idea of the expected behaviour of the floor during under-vehicle explosions can be obtained from the current literature, the limited number of experimental studies that detail methods, results and limitations means that it is difficult to justify the design characteristics of traumatic injury simulators or the validity of numerical efforts. Therefore, the aim of this work was to characterise the behaviour of the floor in an under-vehicle explosion to a range of threats.

\section{Method}

Tests were conducted using the Human Response Test Rig (HRTR) which consists of a blast capsule capable of being launched vertically by either a buried or free-in-air blast load (Figure 1). The blast capsule's loading surface is a rectangular flat armoured steel plate (Weldox $700 \mathrm{E}, \mathrm{SSAB}$, Stockholm, Sweden), $20 \times 2500 \times 2000 \mathrm{~mm}$ in dimensions, which is used as the vehicle-floor surrogate. The plate was bolted under a steel structure with a total of 60 bolts fixed at $150 \mathrm{~mm}$ intervals along the edge of the plate, consisting of a reinforced mild steel support (300 $\mathrm{mm}$ in height) and a mild steel compartment (2500 $\mathrm{mm}$ in height) such that there was an enclosed space above the plate. The structure was designed to weigh approximately $6000 \mathrm{~kg}$ in order to be representative of the mass of a medium size military vehicle. Four poles in each corner were used to guide the vehicle surrogate in the vertical direction. At the bottom of these poles a series of damping elements ensured that the capsule was not damaged when falling back towards the ground following a test. The distance of the armoured plate to the ground (otherwise known as standoff) was set at $750 \mathrm{~mm}$ in order to replicate a typical value seen in the larger vehicles. The test bed was circular in shape with a diameter of $4 \mathrm{~m}$ and depth of $4 \mathrm{~m}$; it was filled with standard builders mix soil and was lined with sandbags and an impermeable membrane.

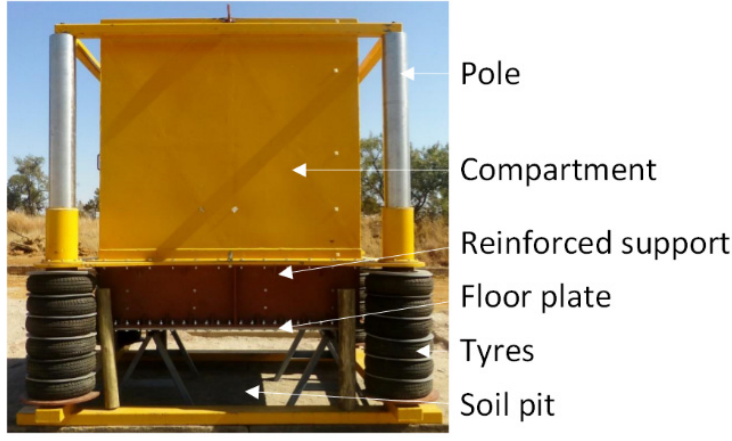

(a)

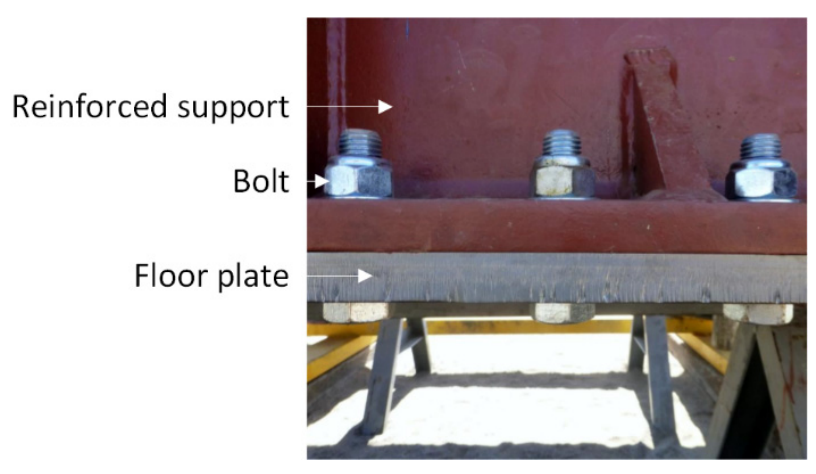

(b)

Figure 1. Photographs of the (a) vehicle surrogate (b) the bolts securing the floor plate beneath the reinforced support

Charges of 1, 3 and $6 \mathrm{~kg}$ of TNT were used. The diameter to height ratio was 5:1, 3:1 and 3:1 for the 1, 3 and $6 \mathrm{~kg}$ charges, respectively. The detonation point was set at depth of $50 \%$ of the explosive height. The charges were initiated axially from the top of the mine. The pentolite booster charge mass was 60,80 and $80 \mathrm{~g}$ for the 1,3 and $6 \mathrm{~kg}$ charges, respectively and the booster orifice was cylindrical running through the middle of the charge with a diameter of $30 \mathrm{~mm}$. A total of 7 tests were carried out in the following sequence. Four tests were carried out with a $1 \mathrm{~kg}$ charge; 2 flush buried and 2 buried $50 \mathrm{~mm}$ beneath the surface. One $3 \mathrm{~kg}$ and two $6 \mathrm{~kg}$ tests were carried out, all of which were flush buried. Prior to each test the moisture, wet density and dry density of the soil were measured at depths of 150 and $300 \mathrm{~mm}$ beneath the rig using a moisture density gauge (3440A, Troxler, NC, USA). The soil was supplemented and raked prior to each test to ensure the surface was flat. The centre of the soil was marked using taught string so that the explosive could be positioned below the centre of the plate.

The behaviour of the floor during the explosions was measured using both accelerometers (350D02, PCB Piezotronics Depew, NY, USA) and Photonic Doppler Velocimetry (PDV). Accelerometers have been widely used to characterise the response of structures to blast loading (Boyd, 2000; Jacinto et al., 2001). While PDV has 
become a standard velocity diagnostic within the shock-physics field (Holtkamp, 2007; Mercier et al., 2008), there are no known instances of its use in experiments of this scale and low velocities. PDV, developed by Strand and Whitworth (2007), emits narrowband light onto the target surface, when the surface accelerates the reflected light is Doppler shifted. In this study the laser source was producing $1550 \mathrm{~nm}$ light with a linewidth of approximately $1 \mathrm{MHz}$. The reflected, Doppler shifted light was then mixed with a reference source to convert the returned signal from $\sim 1014 \mathrm{~Hz}$ to a measurable $\sim 109 \mathrm{~Hz}$. This interfered signal was measured using a high-bandwidth photodetector and recorded with a GHz bandwidth oscilloscope. A diagram of the PDV system used for these tests is shown in Figure 2.

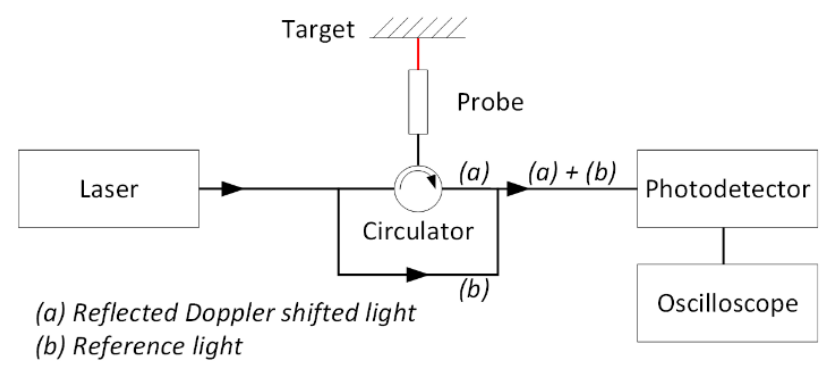

Figure 2. Diagram of the PDV system used for these tests

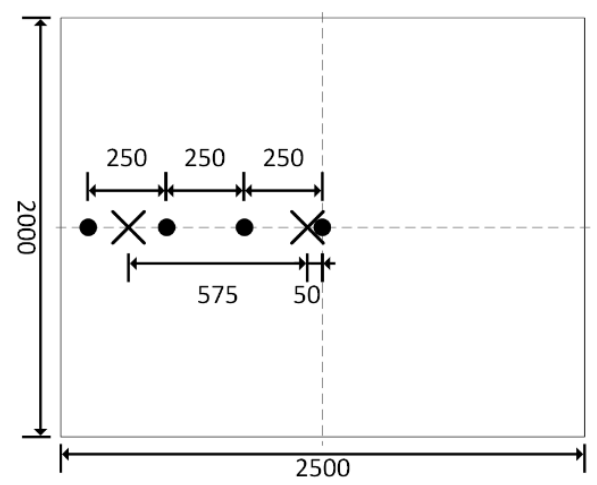

Figure 3. Dimensions and sensor locations of the floor of the surrogate vehicle. All measurements are in $\mathrm{mm}$. Accelerometer locations are indicated with a cross and Het-V sensor locations are indicated with a dot. Not drawn to scale

All sensors were placed along a straight line in the middle of the plate running parallel to the two longest edges (Figure 3). Holes were drilled and tapped such that the accelerometers could be screwed into the plate. The accelerometers were positioned at 2 locations; 50 and $625 \mathrm{~mm}$ from the centre point of the plate. Collimating PDV probes (AC PhotonicsTM) were focused at 4 locations; the centre of the plate, and at 250,500 and $750 \mathrm{~mm}$ from the centre. The PDV probes were fixed to a wooden frame which in turn was clamped to the top of the reinforced support such that the sensors were $250 \mathrm{~mm}$ above the plate at the beginning of the test. Retro-reflective tape was fixed to the floor plates to maximise the reflected PDV light. A tri-axial accelerometer (356A01, PCB Piezotronics Depew, NY, USA) was attached to the wooden frame to confirm that the frame did not move during the time that data was captured using the PDV system. All accelerometer data were recorded at a rate of $200 \mathrm{kHz}$ using a PXIe acquisition system (National Instruments, Austin, TX, USA) which has a built in anti-aliasing filter. The PDV data were recorded using a Digital Phosphor Oscilloscope (DPO4104B, Tektronix, Beaverton, OR, USA) at 1 GS/s and a bandwidth of $5 \mathrm{GHz}$ and processed using custom written MATLAB code (MathWorks, Natick, MA, USA) in order to obtain velocity-time traces. The processing technique involves a fast Fourier transform method using fixed time intervals resulting in a processed-data resolution of approximately $250 \mathrm{MHz}$. Data acquisition from all sensors was triggered from the detonation firing pulse such that the signals were synchronised. Acceleration data were filtered using a low-pass Butterworth filter with a cut off frequency of $4 \mathrm{kHz}$ and then integrated in order to determine the velocity history. Permanent deformation was calculated by measuring the distance from the ground to the bottom of the plate using a laser distance meter (DISTOTM D8, Leica Geomsystems AG, Switzerland, resolution $= \pm 1 \mathrm{~mm}$ ) after the rig had been set up for the next test and the soil beneath the plate had been levelled. 


\section{Results}

Instrumentation failures meant that PDV data was not obtained at any location for tests 1 and $6(1 \mathrm{~kg}$ flush buried and $6 \mathrm{~kg}$ flush buried), and at the furthest location $(650 \mathrm{~mm}$ from the centre) for test 4 . Accelerometer data were not obtained for the location $625 \mathrm{~mm}$ from the centre in tests 1, 3 and 4. Analysis of the data recorded by the triaxial accelerometer attached to the wooden support showed that in the first $1.5 \mathrm{~ms}$ of all tests the wooden frame did not exceed a velocity of $0.06 \mathrm{~m} / \mathrm{s}$ and within the first $4 \mathrm{~ms}$ the velocity did not exceed $0.5 \mathrm{~m} / \mathrm{s}$. As these values were within the noise of the velocity-time trace, the PDV data for the first $4 \mathrm{~ms}$ were deemed accurate. The average wet density of the soil measured prior to each test was $1688 \pm 49 \mathrm{~kg} / \mathrm{m} 3$ (mean \pm 1 standard deviation) across all tests.

A comparison of the typical velocity-time graphs obtained by the PDV at the centre of the plate and by the accelerometer $50 \mathrm{~mm}$ from the centre of the plate in test $2(1 \mathrm{~kg}$, flush buried) is shown in Figure 4. There is good agreement between the accelerometer and the PDV velocity-time data as the velocity rises, however the PDV measures a higher peak in this test. This was a trend seen in all tests.

Peak velocity and time to peak velocity values from all sensor locations and all tests are shown in Figure 5. Peak velocity ranged from 5.8 to $80.5 \mathrm{~m} / \mathrm{s}$ and time to peak velocity ranged from 0.10 to $3.13 \mathrm{~ms}$.

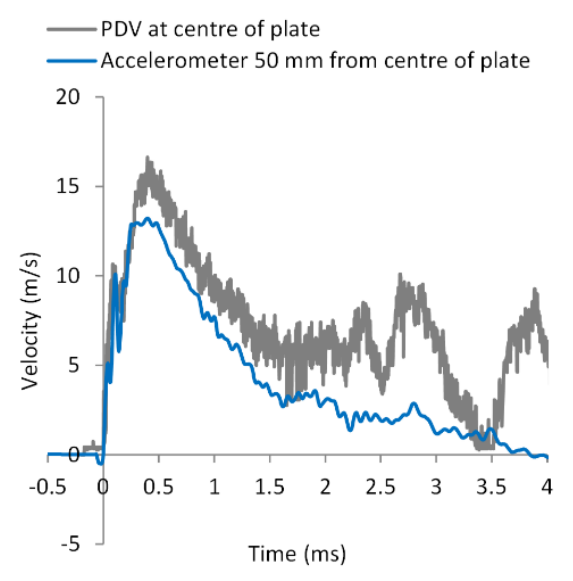

Figure 4. Typical velocity-time graph taken from test 2 (1 kg, flush buried charge). The

PDV data is from the centre of the plate and the accelerometer data is from $50 \mathrm{~mm}$ from the centre

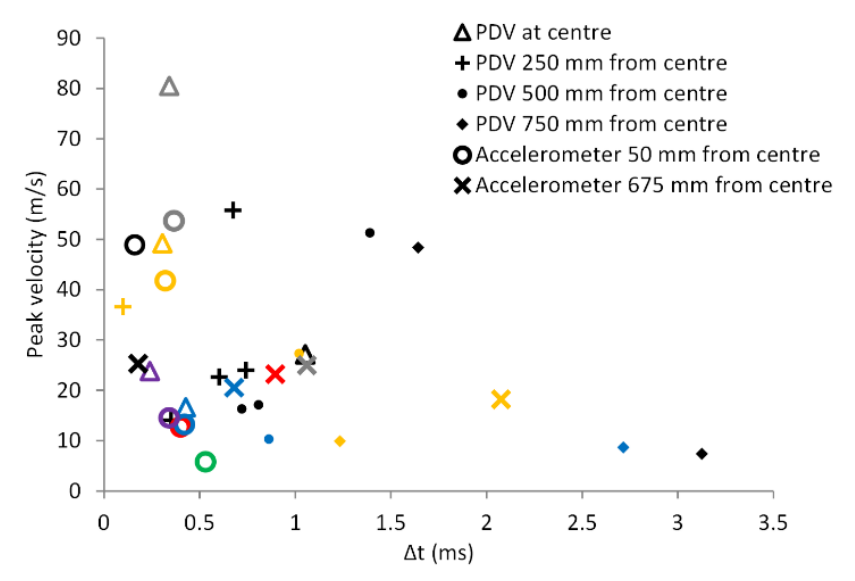

Figure 5. Peak velocity and time to peak velocity for all tests using both the accelerometer and PDV measurements. Each colour represents a different test and each shape represents a different sensor/ sensor location. Test $1-$ Red, $2-$ Blue, 3 - Green, 4 - Purple, 5 - Orange, 6 - Black, 7 - Grey

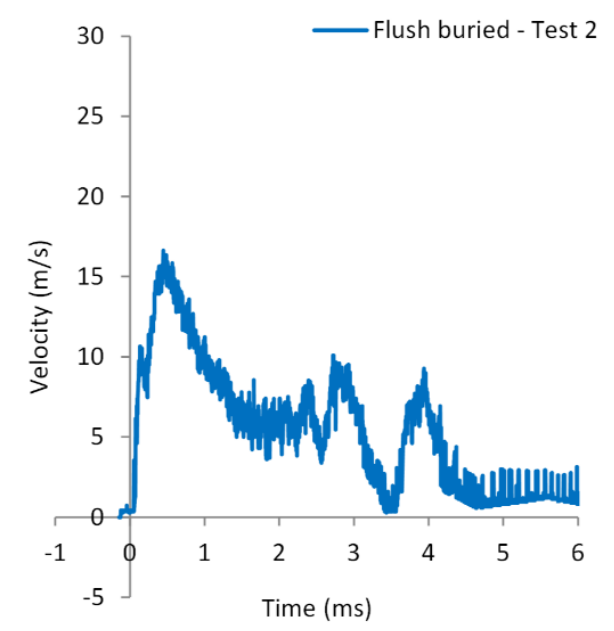

(a)

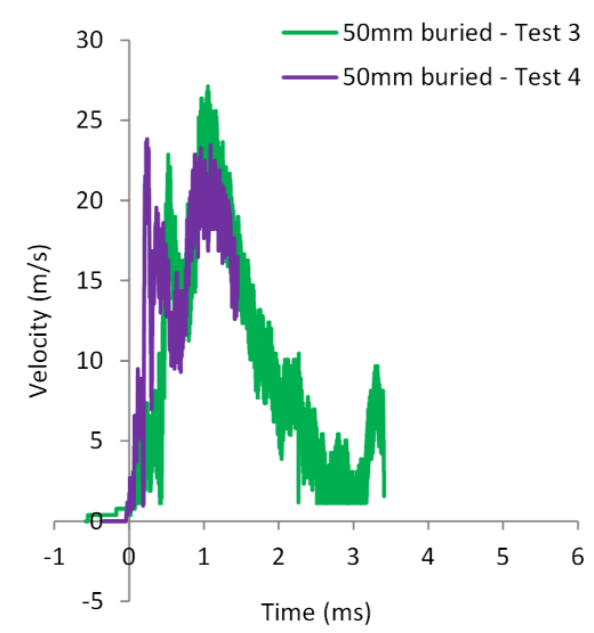

(b)

Figure 6. A comparison of the velocity-time graphs measured at the centre of the plate for the flush buried and $50 \mathrm{~mm}$ deep buried experiments with a $1 \mathrm{~kg}$ charge 
Figure 6 shows a comparison of velocity-time data recorded by the PDV sensor located at the centre of the plate between experiments with the charge flush buried and buried $50 \mathrm{~mm}$ deep. The peak velocity in the $50 \mathrm{~mm}$ buried tests was higher than that seen in the flush buried test however the time to peak was shorter.

A comparison of the PDV velocity-time data for 1, 3 and $6 \mathrm{~kg}$ flush buried experiments can be seen in Figure 7 . Peak velocity reduces and time to peak velocity increases the further away from the centre of the plate for all charge sizes. Peak velocity increases with charge size.

(a)
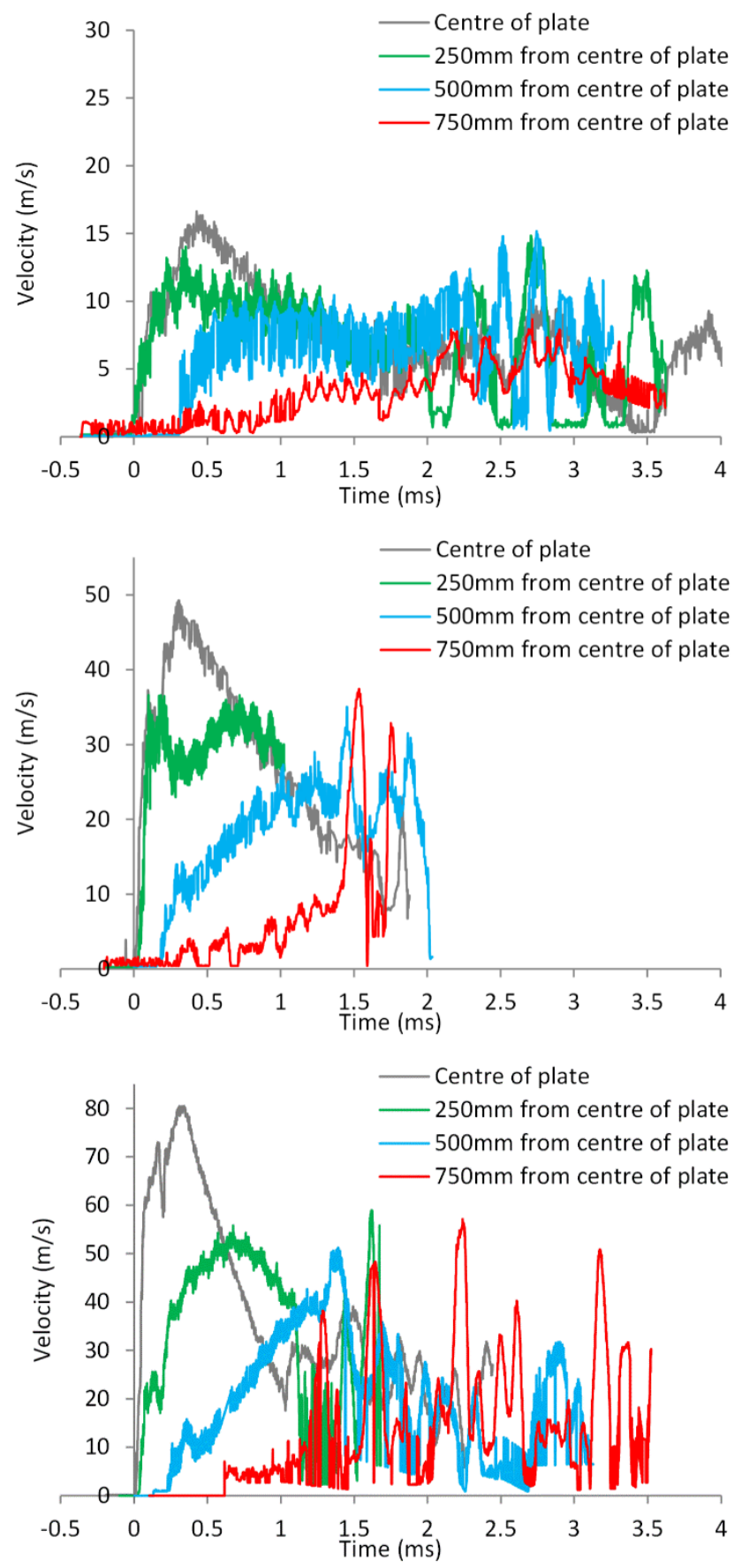

Figure 7. PDV velocity-time data for flush buried tests with (a) 1, (b) 3 and (c) $6 \mathrm{~kg}$ TNT charges

The errors involved in PDV use and analysis are discussed in (Dolan, 2010; Mercier et al., 2006); the variation in velocity seen in the PDV data is to be expected from the velocities and the geometry used. The advantage of using two distinct measuring systems allows comparison; in this case the PDV and accelerometer histories are consistent. 


\section{Discussion}

The results obtained from this set of experiments can provide a range of floor behaviours that might be expected during an under-vehicle explosion.

The peak velocity ranged from 5.8 to $80.5 \mathrm{~m} / \mathrm{s}$ and time to peak velocity ranged from 0.10 to $3.13 \mathrm{~ms}$. The results we obtained here cannot be compared directly with previous work in the literature. The values obtained by Held (2009), $140 \mathrm{~m} / \mathrm{s}$ within $0.16 \mathrm{~ms}$, are within the time to peak boundaries of this range but not within the peak velocity boundaries; however, Held (2009) used a larger charge size ( 8 compared to $6 \mathrm{~kg}$ ), a lower standoff (500 compared to $750 \mathrm{~mm}$ ) and a different material around the charge (a steel pit compared with lying flush on sand). The values predicted by the numerical model of Williams and Fillion-Gourdeau (2002) $(27 \mathrm{~m} / \mathrm{s}$ within $10 \mathrm{~ms})$ were within the peak velocity boundaries but not within the time to peak velocity boundaries. There are a number of factors which may contribute to the longer time to peak velocity predicted by the numerical model; while their charge was similar in terms of size to the largest used in this study, it was buried by $88.1 \mathrm{~mm}$ compared to flush buried, it was not located directly beneath the centre of the floor of the vehicle and, since it was a model of an actual vehicle, the fixation points of the plate are different to those used in this study. The peak velocities used by traumatic injury simulators (Table 1) are within the lower bounds of the range seen in this study however, their time to peak velocities are longer than those seen here.

An important finding from these experiments is the difference that a small distance along the plate makes to the velocity-time trace measured. For example, the peak velocity was $31 \%$ lower $250 \mathrm{~mm}$ from the centre of the plate in comparison to the centre of the plate in test 7 (6 kg, flush buried). In a typical seated posture the distance between the occupant's feet is approximately $250 \mathrm{~mm}$. Therefore, the loading that the two legs of a single occupant experience in a single event may be substantially different and so result in significantly different severities of lower extremity injury; such injury profiles were seen in recent conflicts (Ramasamy et al., 2011a).

A comparison of all of the flush buried tests showed that the relationship between peak velocity and charge size was linear at 0,250 and $500 \mathrm{~mm}$ from the centre of the plate measured by the PDV $\left(\mathrm{R}^{2}>0.974\right)$. At the centre of the plate the gradient of charge size $(\mathrm{kg})$-peak velocity $(\mathrm{m} / \mathrm{s})$ was 12.6 reducing to 8.20 and 8.17 at distances of 250 and $500 \mathrm{~mm}$ from the centre of the plate, respectively, showing that the effect of charge size is greatest at the centre of the plate.

The peak velocity measured in the buried tests was higher (by approximately $35 \%$ ) than that measured in the flush tests. It is possible that this is due to the effects of a plug of soil being thrown against the plate in the buried tests, flush burying the explosive such that there is no soil plug means that most of the impulse is transmitted through the expanding gas, resulting in a significant decrease in impulse in comparison to the buried tests (Genson, 2006). It should be noted that the effect of burying a charge may vary; for example, results obtained by Held (2009) showed that the impulse density (directly related to velocity) was $10 \%$ greater at the charge axis in flush buried tests compared with those buried $100 \mathrm{~mm}$ beneath the surface. The effect is dependent on charge shape, the material in which it is buried and the geometry of the target.

There are a number of potential limitations to this study. A single floor plate was used for all of the tests. Less than $1 \mathrm{~mm}$ of permanent deformation was seen in tests $1-5$ where the charge size was less than $3 \mathrm{~kg}$, however, after the first $6 \mathrm{~kg}$ flush buried test (test 6), $15 \mathrm{~mm}$ of permanent deformation was measured and after the final $6 \mathrm{~kg}$ test (test 7) the plate permanently deformed a further $50 \mathrm{~mm}$. While PDV data was not captured for test 6 , accelerometer data was captured for both the first $6 \mathrm{~kg}$ test (test 6 ) and the repeat (test 7), the fact that these traces were similar gives us confidence that the permanent deformation of the plate had minimal effect on the dynamics measured in test 7. The diameter to height ratio for the $1 \mathrm{~kg}$ tests was different in comparison to the 3 and $6 \mathrm{~kg}$ tests (5:1 compared to 3:1), which may have affected the peak and time to peak velocity seen in the tests with this charge size. Reinecke et al. (2008) detonated $8 \mathrm{~kg}$ charges with diameter to height ratios of both 5:1 and 3:1 beneath a custom built impulse measurement rig. They found that increasing the diameter to height ratio from 3:1 to 5:1 increased the measured impulse by approximately $11 \%$. Another limitation is that it is expected that there was some error in the positioning of the charge, in terms of it being directly beneath the centre of the plate and it being completely parallel to both the ground and the bottom of the plate. However, the similarities in the velocity-time traces recorded for the repeated tests gives confidence that the effect of these errors on the measured dynamic deformation of the floor plate were small.

When interpreting results from these experiments it must be kept in mind that the floor of a vehicle is not as simple in terms of dimensions as the steel plate used here. The irregular geometry of a vehicle floor may mean that the peak velocities do not simply fall away the further the distance from the centre of the plate since the irregular geometries may create areas of weakness that results in high peak velocities. Further experimental or numerical investigations would be necessary to understand these effects. 


\section{Conclusion}

This study used both Photonic Doppler Velocimetry (PDV) and accelerometers to determine the dynamic response of the floor of a surrogate vehicle when exposed to detonation charges between 1 and $6 \mathrm{~kg}$ TNT from underneath. Peak velocity ranged from 5.8 to $80.5 \mathrm{~m} / \mathrm{s}$ and time to peak velocity ranged from 0.10 to $3.13 \mathrm{~ms}$. These data should be taken into consideration when designing vehicle protection and traumatic injury simulators that aim at replicating the loading transferred by the floor to occupants during under-vehicle explosions. Accurate simulation of dynamic response of the floor applied in laboratory studies are vital to enable a greater understanding of human response and human tolerance limits to injury that are relevant to blast-related loading.

\section{Acknowledgments}

This work was conducted under the auspices of the The Royal British Legion Centre for Blast Injury Studies at Imperial College London. Therefore the financial support of the Royal British Legion for NN, WN, WGP and SDM is gratefully acknowledged. The Institute of Shock Physics acknowledges the support of AWE, Aldermaston, UK and Imperial College London. The authors acknowledge the assistance of Dr. David Chapman regarding PDV usage and interpretation, the technical workshops of Imperial College London for their invaluable support and Mr. Frans Beetge (Armscor) for his technical support during testing.

\section{References}

Bailey, A., Christopher, J., Henderson, K., Brozoski, F., \& Salzar, R. S. (2013). Comparison of Hybrid-III and PMHS Response to Simulated Underbody Blast Loading Conditions. In: Proceedings of IRCOBI Conference 2013 (pp. 158-171). Gothenburg, Sweden.

Bailey, A. M., Christopher, J. J., Brozoski, F., \& Salzar, R. S. (2014). Post Mortem Human Surrogate Injury Response of the Pelvis and Lower Extremities to Simulated Underbody Blast. Ann. Biomed. Eng., 43, 19071917. http://dx.doi.org/10.1007/s10439-014-1211-5

Bir, C., Barbir, A., \& Dosquet, F. (2008). Validation of lower limb surrogates as injury assessment tools in floor impacts due to anti-vehicular land mines. Mil. Med., 173, 1180-1184.

Boyd, S. (2000). Acceleration of a plate subject to explosive blast loading-trial results. Melbourne, Australia.

Dolan, D. H. (2010). Accuracy and precision in photonic Doppler velocimetry. Rev. Sci. Instrum., 81, 053905. http://dx.doi.org/10.1063/1.3429257

Freidlander, F. (1946). The diffraction of sound pulses. I. Diffraction by a semi-infinite plate. Proc. R. Soc. Lond. A. Math. Phys. Sci., 186, 322-344.

Genson, K. (2006). Vehicle Shaping for Mine Blast Damage Reduction. University of Maryland, Maryland, USA.

Held, M. (2009). Anti-tank Mine Blast Effects. J. Battlef. Technol., 12, 1-7.

Holtkamp, D. B. (2007). Survey Of Optical Velocimetry Experiments - Applications Of PDV, A Heterodyne Velocimeter. In IEEE International Conference on Megagauss (pp. 119-128). http://dx.doi.org/10.1109/ MEGAGUSS.2006.4530668

Horst, M., \& Van der, S. C. (2005). Occupant lower leg injury assessment in landmine detonations under a vehicle. In IUTAM Symposium on Impact Biomechanics: From Fundamental Insights to Applications Solid Mechanics and Its Applications (pp. 41-49).

Jacinto, A., Ambrosini, R., \& Danesi, R. (2001). Experimental and computational analysis of plates under air blast loading. Int. J. Impact Eng., 25, 927-947.

Manseau, J., \& Keown, M. (2005). Evaluation of the Complex Lower Leg (CLL) for its use in Anti-Vehicular Mine Testing Applications. In Proceedings of IRCOBI Conference 2005. Prague, Czech Republic.

Manseau, J., \& Lapointe, J. (2005). Evaluation of the Complex Lower Leg (CLL) Under Anti-Vehicular Blast Landmine Loading - TROSSTM Trials in Germany, July 2003.

Masouros, S. D., Newell, N., Ramasamy, A., Bonner, T. J., West, A. T. H., ... Bull, A. M. J. (2013). Design of a traumatic injury simulator for assessing lower limb response to high loading rates. Ann. Biomed. Eng., 41, 1957-1967. http://dx.doi.org/10.1007/s10439-013-0814-6

McKay, B., \& Bir, C. (2008). Development of a lower extremity injury criterion for military vehicle occupants involved in explosive blast events. Pers. armour Syst. Symp. 2008.

McKay, B. J. (2010). Development of lower extremity injury criteria and biomechanical surrogate to evaluate military vehicle occupant injury during an explosive blast event. PhD Thesis. Wayne State University, MI, 
USA, Detroit, Michigan, USA.

Mercier, P., Benier, J., Azzolina, A., Lagrange, J. M., \& Partouche, D. (2006). Photonic doppler velocimetry in shock physics experiments. J. Phys. IV, 134, 805-812. http://dx.doi.org/10.1051/jp4:2006134124

Mercier, P., Bénier, J., Frugier, P. A., Contencin, G., Veaux, J., Lauriot-Basseuil, S., \& Debruyne, M. (2008). Heterodyne velocimetry and detonics experiments, in: Kleine, H., Butron Guillen, M.P. (Eds.), Proceedings of 28th International Congress on High-Speed Imaging and Photonics. International Society for Optics and Photonics (pp. 71261O-10). http://dx.doi.org/10.1117/12.820433

North Atlantic Treaty Organisation HFM-090 TG 25. (2007). Test methodology for protection of vehicle occupants against anti-vehicular landmine and/or IED effects (HFM-090), RTO Technical Report HFM-090, .... Brussels, Belgium.

Pandelani, T., Reinecke, D., Philippens, M., Dosquet, F., \& Beetge, F. (2010). Practical evaluation of the MiL-Lx lower leg when subjected to simulated vehicle under belly blast load conditions, in: Proccedings of the Personal Armour Systems Symposium. Quebec City, Canada, p. 10.

Quenneville, C. (2010). Development of an apparatus to produce fractures from short-duration high-impulse loading with an application in the lower leg. J. Biomech. Eng., 132, 014502.

Ramasamy, A., Hill, A. M., Masouros, S., Gibb, I., Bull, A. M. J., \& Clasper, J. C. (2011a). Blast-related fracture patterns: a forensic biomechanical approach. J. R. Soc. Interface, 8, 689-698. http://dx.doi.org/10.1098/ rsif.2010.0476

Ramasamy, A., Hill, A. M., Phillip, R., Gibb, I., Bull, A. M. J., \& Clasper, J. C. (2011b). The modern “deck-slap" injury--calcaneal blast fractures from vehicle explosions. J. Trauma, 71, 1694-8. http://dx.doi.org/10.1097/ TA.0b013e318227a999

Ramasamy, A., Masouros, S. D., Newell, N., Hill, A. M., Proud, W. G., Brown, K. A., Bull, A. M. J., \& Clasper, J. C. (2011c). In-vehicle extremity injuries from improvised explosive devices: current and future foci. Philos. Trans. R. Soc. Lond. B. Biol. Sci., 366, 160-70. http://dx.doi.org/10.1098/rstb.2010.0219

Reinecke, J., Snyman, I., Ahmed, R., \& Beetge, F. (2008). Safe and secure South Africa: Blast Characterisation through Impulse Measurements In Proceedings of 2nd CSIR Biennial Conference. Pretoria, SA.

Strand, O., Whitworth, T., 2007. Using the heterodyne method to measure velocities on shock physics experiments, In Proceedings of the SCCM Conference (pp. 1143-1146). American Institute of Physics.

Wang, J., Bird, R., Swinton, B., \& Krstic, A. (2001). Protection of lower limbs against floor impact in army vehicles experiencing landmine explosion. $J$ Battlef. Tech., 4, 11-15.

Williams, K., \& Fillion-Gourdeau, F. (2002). Numerical simulation of light armoured vehicle occupant vulnerability to anti-vehicle mine blast. In 7th International LS-DYNA Users Conference. MI, USA.

Yoganandan, N., Pintar, F. A., Schlick, M., Humm, J. R., Voo, L., Merkle, A., \& Kleinberger, M. (2015). Vertical accelerator device to apply loads simulating blast environments in the military to human surrogates. $J$. Biomech., 48, 3534-8. http://dx.doi.org/10.1016/j.jbiomech.2015.06.008

\section{Copyrights}

Copyright for this article is retained by the author(s), with first publication rights granted to the journal.

This is an open-access article distributed under the terms and conditions of the Creative Commons Attribution license (http://creativecommons.org/licenses/by/3.0/). 